\title{
Experimental and statistical study on the irregularity of carbonation depth of cement mortar under supercritical condition
}

\author{
Hao Bao ${ }^{\mathrm{a}}$, Min $\mathrm{Yu}^{\mathrm{a},{ }^{*}}$, Yu Liu ${ }^{\mathrm{a}}$, Jianqiao Ye $\mathrm{e}^{\mathrm{a}, \mathrm{b},{ }^{*}}$ \\ a. Department of Civil Engineering, Wuhan University, Wuhan, China \\ b. Department of Engineering, Lancaster University, Lancaster LA1 4YR, UK \\ *Correspondence author: ceyumin@whu.edu.cn (M. Yu), j.ye2@lancaster.ac.uk (J. Ye)
}

\begin{abstract}
The heterogeneity of a cement-based material results in a random spatial distribution of carbonation depth. Currently, there is a lack of both experimental and numerical investigations aiming at a statistical understanding of this important phenomenon. This paper presents both experimental and numerical supercritical carbonation test results of cement mortar blocks. The carbonation depths are measured along the carbonation boundary by the proposed rapid image processing technique, which are then statistically studied by calculating, e.g., their probability density and power spectral density (PSD). The results indicate that the distribution of the carbonation depth can be approximately represented by a lognormal distribution function and the PSD has quantitative correlation with some of the statistic parameters used in the simulations. In particular, the effects of the autocorrelation lengths and the coefficient of variation of porosity, which are used to define the random porosity field, on the irregularity of carbonation depth are analyzed numerically in details and validated by experimental results. The study has shown that using a random field of porosity with due consideration of spatial correlation and variance, the irregularity of carbonation depth can be realistically captured by the numerical model. The numerical results confirm that lognormal distributions represent the random nature of carbonation depth well and the average and variance of the irregular carbonation depth increase with the increase of carbonation time, autocorrelation length and coefficient of variation of porosity. The study also offers a potential method to numerically calibrate some of the statistic parameters required by a numerical carbonation model through comparing the PSD with that from experimental tests. Overall the methodology adopted in the paper can provide a foundation for future investigations on probability analysis of carbonation depth and other similar work based on multi-scale and -physics modelling.
\end{abstract}

Keywords: Carbonation depth, Cement mortar, Irregularity, Power spectral density, Supercritical carbonation.

\section{Introduction}

Carbonation of cement-based materials is a complex multi-physics process ${ }^{[1-5]}$, involving chemical reactions of $\mathrm{CO}_{2}$ with $\mathrm{CH}$ and C-S-H; gas-liquid two phase flow; dispersion and diffusion of $\mathrm{CO}_{2}$ in water and temperature propagation. Extensive research has been carried out on natural and accelerated carbonation, including the reviews on carbonation of cement-based materials ${ }^{[6,7]}$ and the life prediction model of cementbased materials under natural carbonation ${ }^{[8,9]}$. However, when the temperature and pressure exceed $304.12 \mathrm{~K}$ and $7.38 \mathrm{MPa}$, which are their respective critical values, $\mathrm{CO}_{2}$ is in a supercritical fluid state that has a similar density of fluid and can diffuse through porous materials, such as cement-based materials, like a gas ${ }^{[10]}$. When the state of $\mathrm{CO}_{2}$ is between supercritical fluid state and natural atmospheric environment, the carbonation of 
cement-based materials belongs to accelerated carbonation. Techniques have been developed in recent years to take advantages of the above carbonation processes to, e.g., modify composition and microstructure of cementbased materials ${ }^{[1-13]}$ and to improve material properties using $\mathrm{CO}_{2}$ curing ${ }^{[14-16]}$. The techniques have also important applications in $\mathrm{CO}_{2}$ capture and storage ${ }^{[1]}$, carbonation of hazardous water materials ${ }^{[17-19]}$ and treatment of recycled concrete ${ }^{[20-22]}$.

Carbonation depth is one of the most important characteristics that are used to define the extent of the chemical process taken place during carbonation. Experimental research has shown that under both natural ${ }^{[23]}$ and supercritical ${ }^{[3,24]}$ conditions, the boundary topography of a carbonation zone is irregular, characterized by a random distribution of depth along the boundary with distinctive maximum and minimum. However, current theoretical and numerical models are almost exclusively based on the assumption that the materials are isotropic and homogenous ${ }^{[25]}$, resulting in an uniform carbonation depth ${ }^{[26]}$. There are very limited research on the irregularities of carbonation depth, including Huang, et al. ${ }^{[27]}$ and Ruan, et al. ${ }^{[28]}$ 's studies on the carbonation process of concrete where a non-uniform distribution of carbonation depth was observed by considering the influence of aggregates.

It can be concluded that that it was the heterogeneity of cement-based materials that contributes mostly to the observed randomness ${ }^{[29]}$. This includes the presence of coarse aggregates ${ }^{[30,31]}$, the carbon dioxide gas diffusion paths caused by distribution of cracks ${ }^{[31,32]}$ and the randomly distributed porosity of cement mortar ${ }^{[24]}$. To study the irregularity of carbonation depth, Huang, et al. ${ }^{[27]}$ found that the variation of carbonation depth increased with increased use of coarse aggregates. Jiang, et al. ${ }^{[33]}$ proposed a normal distribution model for carbonation depth in fatigue-damaged concrete and found that the probability distributions of carbonation depth were comparable with realistic frequency distribution histograms. However, apart from revealing the random nature of carbonation depth, there is a lack of quantitative assessment on its random distribution in the current literature.

How to quantitatively describe the topography of rough carbonation front is one of the challenging issues preventing an insight understanding of this important phenomenon. A quantitative description of this randomness front is important in many aspects in terms of not only providing a fundamental understanding of the carbonation process, but also providing a quantitative tool for evaluating material property changes due to carbonation and assessing, e.g., occurrence of steel corrosion due to $\mathrm{CO}_{2}$ penetration. A literature review by the authors showed that power spectral density (PSD) is a powerful quantitative tool to measure a randomly distributed subject. For instance, researchers have used PSD to quantitatively characterize the topography of a rough surface so that the roughness could be further considered in estimating its impact on the mechanical and chemical properties of a material. PSD is a mathematical tool that decomposes a random signal into contributions from different spatial frequencies (wavevectors). Mathematically, PSD is a Fourier transform of the autocorrelation function of a signal, which contains just the power (and not the phase) across a range of wavevectors ${ }^{[34,35]}$. There are some applications of the spectral analysis in civil engineering, such as stochastic content of aggregate shape profiles ${ }^{[36]}$, inelastic torsional response of buildings ${ }^{[37]}$ and monitoring of corrosion of rebar embedded in mortar ${ }^{[38]}$. The primary utility of PSD in the above studies is that it contains unbiased statistical information on the randomness of objectives ${ }^{[39]}$. However, to the authors' best knowledge, there have been no attempts made to use PSD to describe carbonation depth. In addition, since PSD can provide a quantitative description of a random distribution, it can be used in a carbonation analysis to quantitatively determine the influences of 
materials, geometric and spatial parameters that define, e.g., randomness of porosity, on carbonation depth through comparisons between the PSD of experimental results and that of numerical models.

Due to the complex nature of the problem, this paper attempts, as a pioneer work, to focus on investigating the irregularity of carbonation depth of cement mortar caused by randomly distributed porosity before it can be developed further to include aggregates and micro cracks. Both supercritical carbonation experiments and multiphysics numerical simulations are carried out. The numerical simulations are based on the multi-physics model developed and validated previously by the authors ${ }^{[24]}$, by which random porosity of cement mortar can be considered. An image processing technique is proposed in this paper for the spectral analysis of the experimental results. The probability density function and the PSD of carbonation depth from both experimental and numerical studies are found and discussed. The effects of some of the statistics factors, such as the autocorrelation spatial lengths and the coefficient of variation of porosity, on the carbonation depth are also discussed in this paper.

\section{Experimental investigation on the irregularity of carbonation depth}

\subsection{Specimens preparation and mercury intrusion porosimetry}

Cement mortar cubes with a dimension of $100 \mathrm{~mm} \times 100 \mathrm{~mm} \times 100 \mathrm{~mm}$ were cast for mercury intrusion porosimetry (MIP) to measure the average porosity of the material. The mix design proportions are given in Table 1 . The specified 28-day cubic compressive strength of the cubes is $30 \mathrm{MPa}$. Ordinary Portland cement type P.O 42.5 was used as the binder for the mixtures. Normal river sands with fineness modulus of 2.7 were used as the fine aggregates.

\section{Table 1}

Mixture proportions $\left(\mathrm{kg} / \mathrm{m}^{3}\right)$.

\begin{tabular}{llllll}
\hline & Cement & Water & Sand & Gravel & water-binder ratio \\
\hline Cement mortar & 444.4 & 222.2 & 1333.3 & - & 0.5 \\
\hline
\end{tabular}

Twenty-one cement mortar cubes were cast for the MIP and supercritical carbonation tests. After casting, the test specimens were covered with plastic sheets, and left in the casting room for $24 \mathrm{hrs}$. The specimens were then demolded and placed into a standard curing room with a constant temperature of $20^{\circ} \mathrm{C}$ and humidity of $95 \%$ until the 28-day strength was achieved. Eighteen of the cured cubes were divided into 3 groups, each of which had six samples, for the supercritical carbonation test. The remaining three cubes were used for the MIP.

MIP is a widely-used technique for characterizing the distribution of pore sizes in cement-based materials. Three small cubic samples of approximately $1 \mathrm{~cm}^{3}$ were taken at different locations of the cement mortar cubes mentioned above and tested by mercury intrusion porosimetry to obtain the average porosity of the cement mortar cube. The samples were then immersed in absolute ethyl alcohol to avoid further hydration. The threshold pressure was 7.11 Pisa for MIP. Fig. 1 shows cumulative mercury intrusion versus pore size diameter of the three small samples. The porosities were estimated at $11.5 \%, 10.8 \%, 13.5 \%$, respectively, for samples A, B and C, which gave an average of $12.0 \%$. The average value will be used in the following Sections as the average porosity of the cement mortar before carbonation. During the MIP, It was also found that the size of the pores ranged from $3 \mathrm{~nm}$ to $90 \mu \mathrm{m}$. 


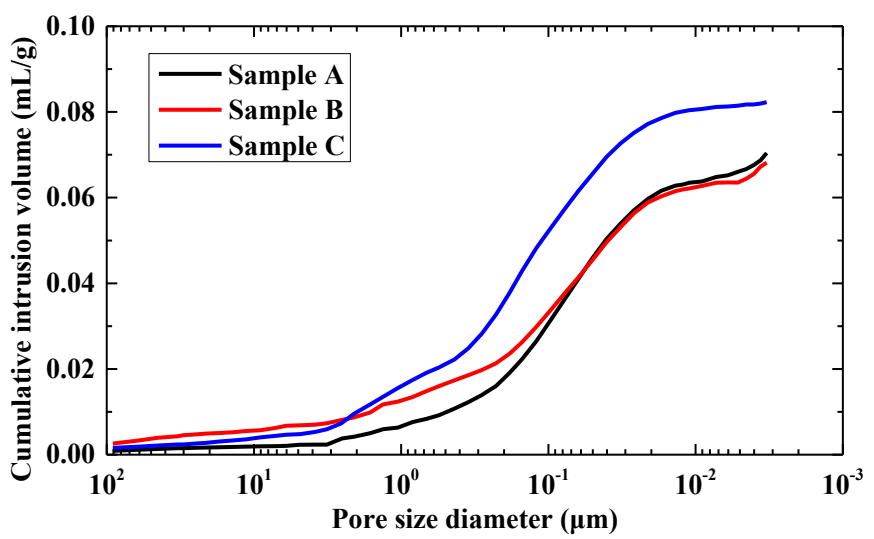

Fig. 1. Cumulative mercury intrusion vs. pore size diameter curve

\subsection{Supercritical carbonation tests: procedure and setup}

The supercritical carbonation tests were performed using a closed-cycle carbonation system that includes a sealed chamber, a vacuum pump, an air compressor, a booster pump and a $\mathrm{CO}_{2}$ cylinder unit, as shown in Fig. $\underset{\rightarrow}{2}$. Fig. 2 also shows that a temperature data logger, a pressure gauge and heating rods are mounted to the sealed chamber. For a typical test, 6 cubes can be placed in the chamber.

Before $\mathrm{CO}_{2}$ gas injection, the chamber was vacuumed to -0.98 bar by the vacuum pump. $\mathrm{CO}_{2}$ gas was injected to the chamber driven by the pressure gradient between the $\mathrm{CO}_{2}$ tank and the chamber. The $\mathrm{CO}_{2}$ pressure and temperature in the chamber were controlled by a gas regulator. When the pressure in the $\mathrm{CO}_{2} \operatorname{tank}$ was reduced and close to that of the chamber, the air compressor started to run to maintain the injection flow until the desired pressure and temperature in the chamber were achieved and kept at a constant level.

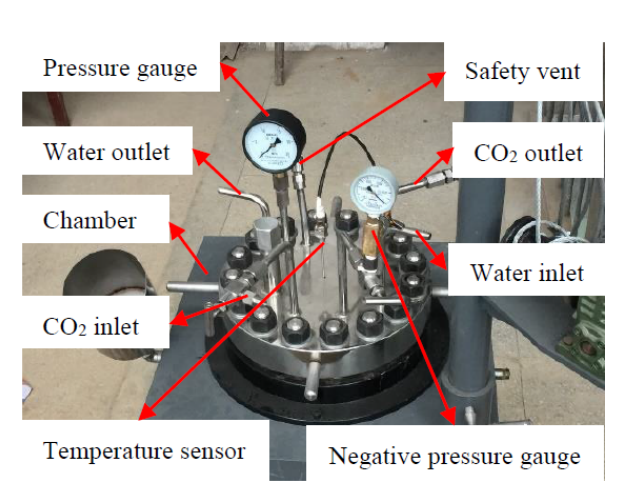

a) Test setup

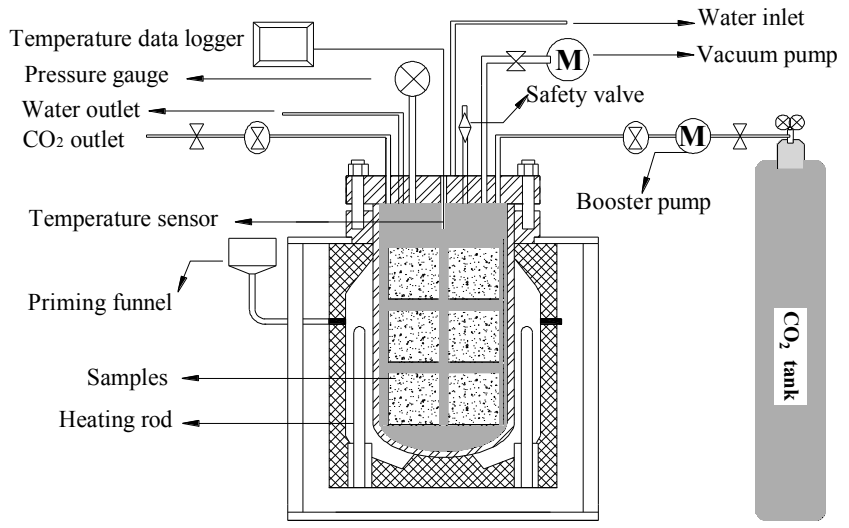

b) Details of reaction still

Fig. 2. Closed-cycle carbonation system

The three groups of cubes were then carbonated to three different time periods with the temperature and atmospheric pressure exceeding, respectively, $304.12 \mathrm{~K}$ and $7.38 \mathrm{MPa}$. The pressure and temperature in the chamber were constantly monitored and recorded, as shown in Fig. 3 (a), where the total carbonation time includes the inflating time, the supercritical carbonation time and the $\mathrm{CO}_{2}$ recycling time, denoted, respectively, by the ascending, plateaued and descending branches. From some preliminary results, which are not included here, it was observed that a minimum of 2-3 hours supercritical carbonation period was required for reliable data processing and a much longer carbonation time would lead to full carbonation with no or very short carbonation boundary to be analyzed. Therefore, $3 \mathrm{~h}, 4 \mathrm{~h}$ and $5 \mathrm{~h}$ supercritical carbonation times were selected to monitor the time dependent carbonation depth. In addition, time was also required to inject $\mathrm{CO}_{2}$ before the supercritical 
pressure was reached and to recycle the $\mathrm{CO}_{2}$ to depressurize the chamber. The total carbonation time were, respectively, 4.5 h, $5.7 \mathrm{~h}$ and $7.5 \mathrm{~h}$, as shown in Figs. 4 (a-c).

Figs. 3 (a), (b) and (c) show the respective recorded temperature and pressure for a total carbonation time of $4.5 \mathrm{~h}, 5.7 \mathrm{~h}$ and $7.5 \mathrm{~h}$, in which the respective supercritical carbonation times are $3 \mathrm{~h}, 4 \mathrm{~h}$ and $5 \mathrm{~h}$.

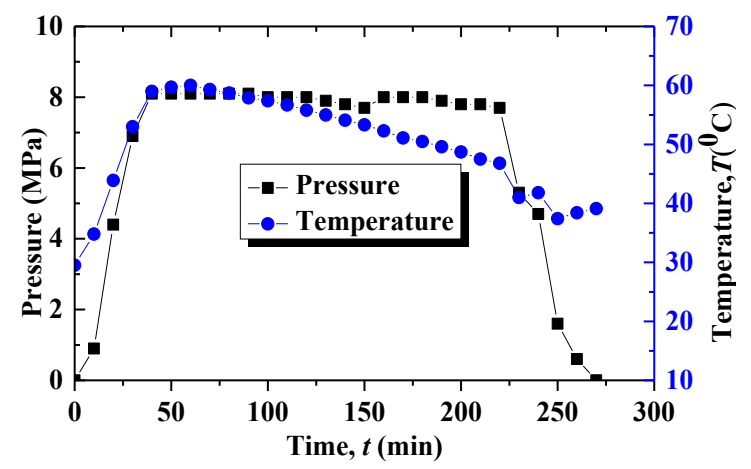

a) Group 1: Carbonated for $4.5 \mathrm{~h}$ (supercritically carbonated for $3 \mathrm{~h}$ )

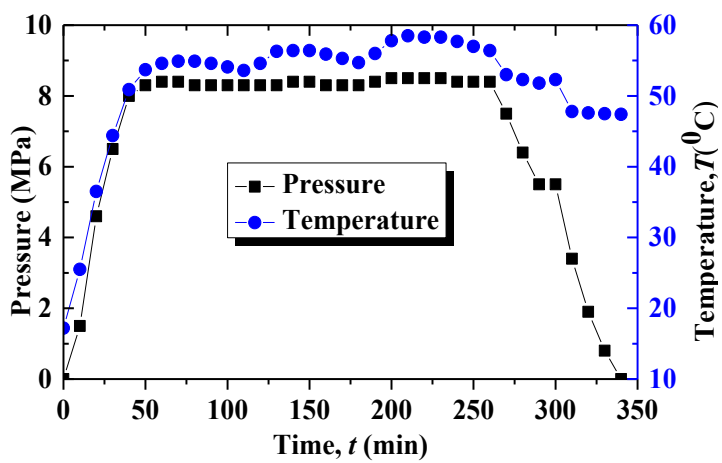

b) Group 2: Carbonated for $5.7 \mathrm{~h}$ (supercritically carbonated for $4 \mathrm{~h}$ )

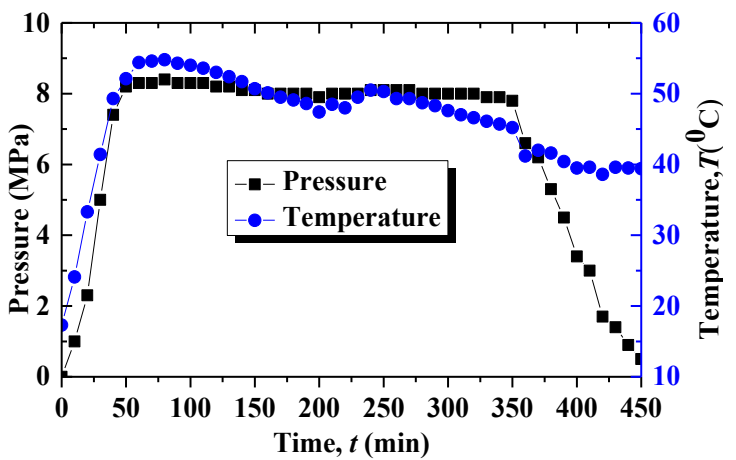

c) Group 3: Carbonated for $7.5 \mathrm{~h}$ (supercritically carbonated for $5 \mathrm{~h}$ )

Fig. 3. Conditions of supercritical carbonation

After the supercritical carbonation process was completed, the $\mathrm{CO}_{2}$ gas was recycled to the $\mathrm{CO}_{2}$ tank. The carbonated cement cubes were removed from the chamber.

\subsection{Test results of supercritical carbonation}

The carbonated cement cubes removed from the chamber were cut into two halves. The fresh cuts of the cubes were polished and cleaned. Phenolphthalein solution was sprayed on the cuts to reveal any non-carbonated zones identified by pink color, which also revealed the boundaries separating the carbonated and non-carbonated zones on the cuts. The colored surfaces were then scanned by a scanner. The scanned images are shown in Figs. $4(\mathrm{a}),(\mathrm{b})$ and (c), showing the cuts from the cubes carbonated for $4.5 \mathrm{~h}, 5.7 \mathrm{~h}$ and $7.5 \mathrm{~h}$, respectively. As shown 
in Fig. 4 , the non-carbonized zones are all around the centers of the blocks and all have irregular boundaries of random nature. As a result, the maximum and minimum carbonation depths on a cut are shown, and are also of random nature.

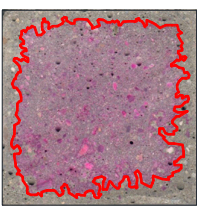

Sample-1

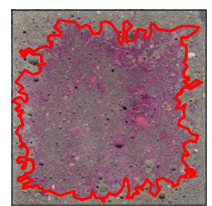

Sample-2

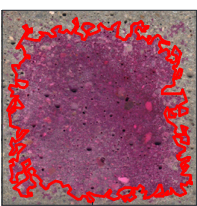

Sample-3

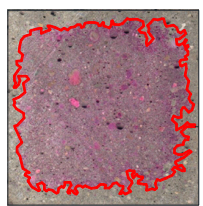

Sample-4

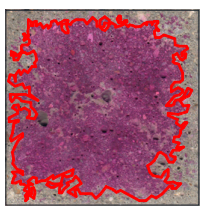

Sample-5

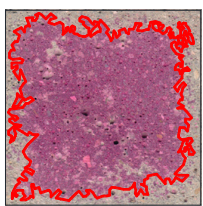

Sample-6

a) Group 1: 4.5 hours carbonation (supercritically carbonated for $3 \mathrm{~h}$ )

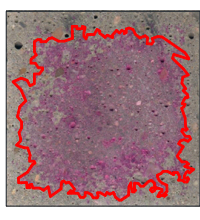

Sample-7



Sample-8



Sample-9

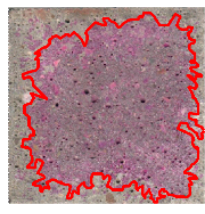

Sample-10

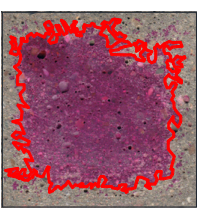

Sample-11

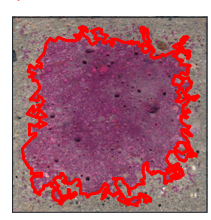

Sample-12

b) Group 2: 5.7 hours carbonation (supercritically carbonated for $4 \mathrm{~h}$ )

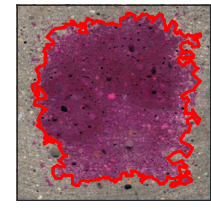

Sample-13



Sample-14



Sample-15

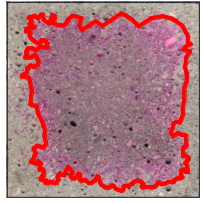

Sample-16

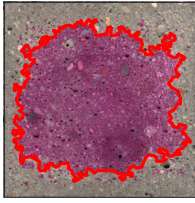

Sample-17

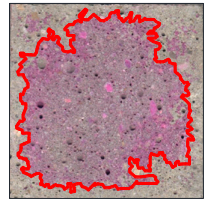

Sample-18

c) Group 3: 7.5 hours carbonation (supercritically carbonated for $5 \mathrm{~h}$ )

Fig. 4. Test results of supercritical carbonation of cement mortar

\section{Analysis of the irregularity of the experimental carbonation depth}

\subsection{Imaging processing of the irregular carbonation depth}

Fig. $\mathbf{5}$ (a) shows the carbonation boundary of the first sample in Fig. 4 (a), which was from the scan image processed by Matlab as an assembly of pixels. To plot the carbonation depth against the location along the boundary in a rectangular co-ordinate system, the four corner points, identified as A, B, C and D at the carbonation boundary, are first located. The four points have the shortest distances to their respective nearest vertices formed by the edges of the section, as shown in Fig. 5 (a). Starting from point A, the distances from the carbonation boundary to the edge of the cube were measured and are presented as the carbonation depth in Fig. $\underline{\mathbf{5}}$ (b). In addition, by following this process, the measured carbonation depths under the small areas close to both sides of a corner were moved from data to be processed, which was intended to reduce the influences of higher area of $\mathrm{CO}_{2}$ penetration around corners. This can be seen from Fig. $\mathbf{5}(\mathrm{b})$ where the measured carbonation depth is along a length (the horizontal axis) that is shorter than $400 \mathrm{~mm}$. We have also compared the carbonation depths, including the average, maximum and minimum depths, and the PDS measured from the image process described below with those measured only from the middle $50 \mathrm{~mm}$ of each sides. The comparisons have shown that no significant differences between the two sets of results. Therefore, we assume that the corner effect after the image process on the test results is not significant. 


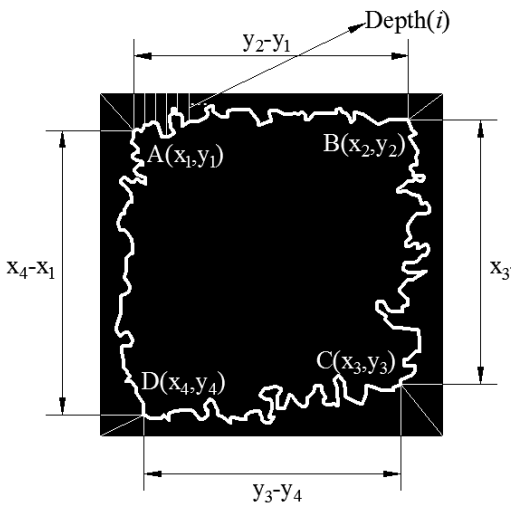

a) Binary image

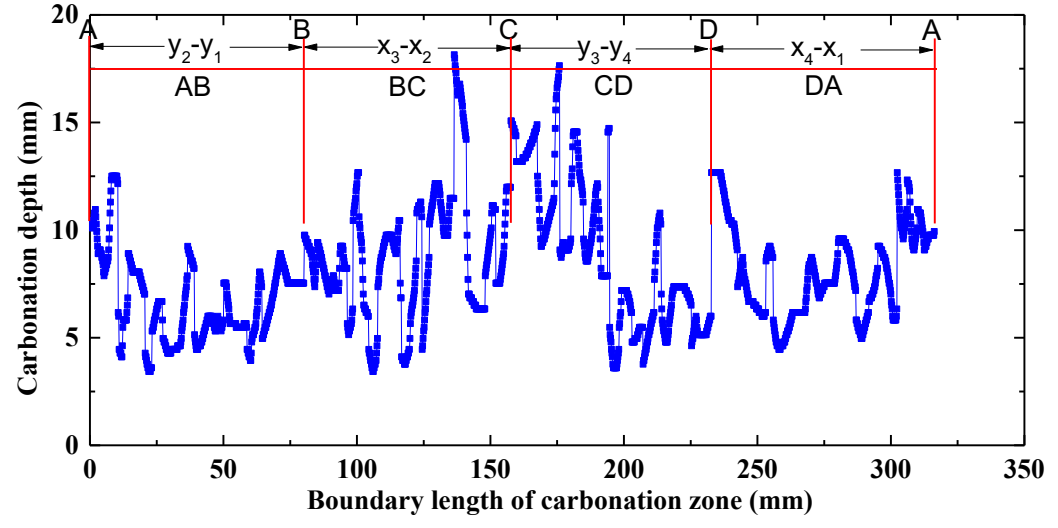

b) Distribution of carbonation depth

Fig. 5. Distribution of the measured carbonation depth of sample-1

The above procedure was applied to all the samples shown in Fig. 4 to record the distribution of the carbonation depths of all the tested cement mortar blocks carbonated, respectively, for 4.5, 5.7 and 7.5 hours. In summary, the carbonation depths of all the samples starting from point A are shown in Fig. $\underline{\mathbf{6}}$, where the average carbonation depths of each samples are also shown. There is no question that the carbonation depths are randomly distributed for all the cases.

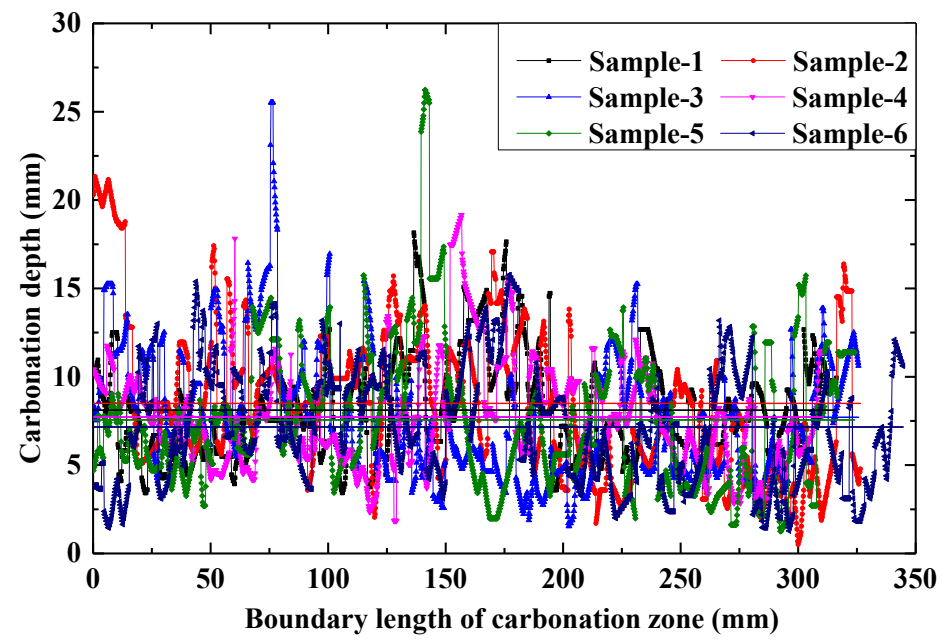

a) Group 1: 4.5 hours carbonation

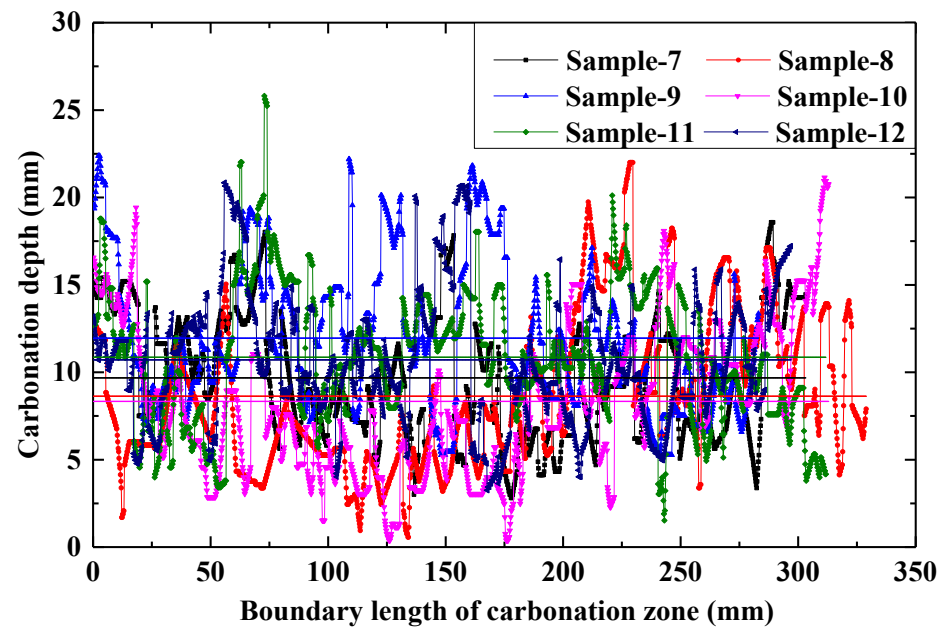

b) Group 2: 5.7 hours carbonation 


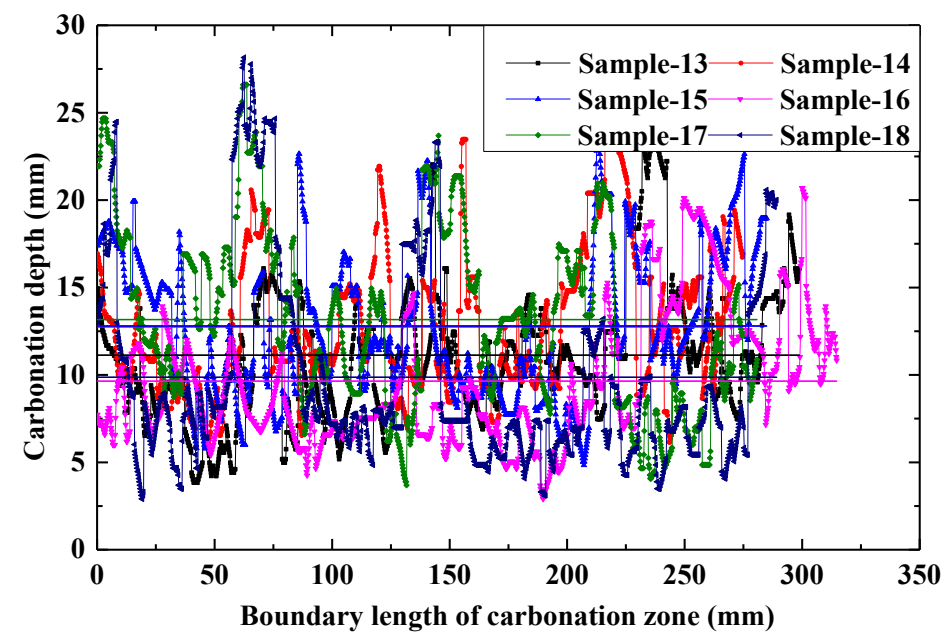

c) Group 3: 7.5 hours carbonation

Fig. 6. Distribution of carbonation depth along the boundary of carbonation zone

\subsection{Average and variance of the irregular experimental carbonation depth}

In this section, the randomly distributed carbonation depths of the tested blocks are characterized by their average, maximum and minimum carbonation depths, which are extracted from Fig. $\mathbf{6}$ and presented in Fig. $\mathbf{7}$; It can be seen that within a group of the cement mortar blocks, the average carbonation depths across the 6 samples agree with each other reasonably well, while the maximum and minimum carbonation depths across the six samples exhibit greater discrepancies.

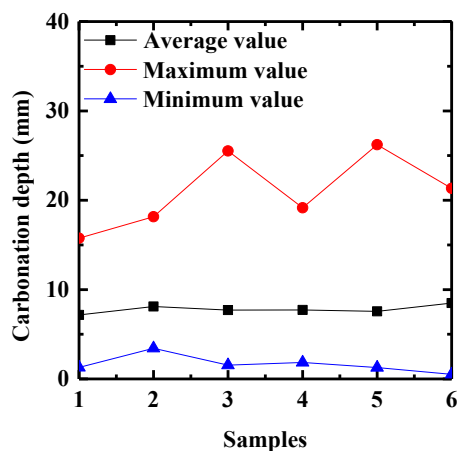

a) 4.5 hours carbonation

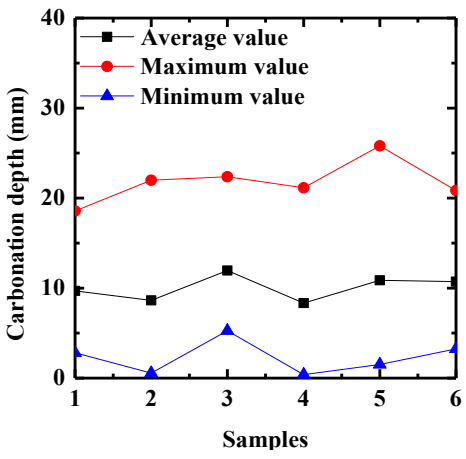

b) 5.7 hours carbonation

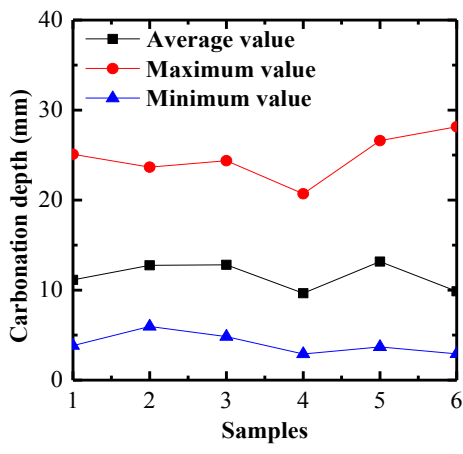

c) 7.5 hours carbonation

Fig. 7. Test results of carbonation depth of the cement mortar samples

Table 2 presents the average carbonation depths and their variances across the six samples of each groups. As expected, the results show that both the average and the variance of the carbonation depths from the experiments increase with the increase of carbonation time.

\section{Table 2}

Average values of average carbonation depth and their variances of test blocks.

\begin{tabular}{llll}
\hline \multirow{2}{*}{ Group } & Carbonation time, $T(\mathrm{~h})$ & Average value & \\
\cline { 3 - 4 } & & Average carbonation depth, $\mu_{l}(\mathrm{~mm})$ & Variance, $v_{l}\left(\mathrm{~mm}^{2}\right)$ \\
\hline Group 1 & 4.5 & 7.8 & 12.4 \\
Group 2 & 5.7 & 10.0 & 15.8 \\
Group 3 & 7.5 & 11.6 & 20.4 \\
\hline
\end{tabular}


There have been studies done on the statistical analysis of accelerated and natural carbonation depth by applying normal distribution ${ }^{[33]}$ and lognormal distribution functions ${ }^{[40]}$, respectively. In order to study the distribution characteristics of supercritical carbonation depth, both the normal distribution function and lognormal distribution function were applied and compared in this paper. The respective probability density functions of the above two distributions are shown by Eq. ((1) and Eq. ((2). The relationship between the average, $\mu_{1}$, standard deviation, $\sigma_{1}, \log$ average, $\mu_{2}$ and log standard deviation, $\sigma_{2}$, are shown in Eq. ((3) and Eq. ((4):

$$
\begin{gathered}
f_{1}(x)=\frac{1}{\sqrt{2 \pi} \sigma_{1}} \exp \left[-\frac{\left(x-\mu_{1}\right)^{2}}{2 \sigma_{1}^{2}}\right] \\
f_{2}(x)=\frac{1}{x \sigma_{2} \sqrt{2 \pi}} \exp \left[-\frac{\left(\ln x-\mu_{2}\right)^{2}}{2 \sigma_{2}^{2}}\right] \\
\mu_{2}=\ln \left(\frac{\mu_{1}^{2}}{\sqrt{\sigma_{1}^{2}+\mu_{1}^{2}}}\right) \\
\sigma_{2}=\sqrt{\ln \left(\frac{\sigma_{1}^{2}}{\mu_{1}^{2}}+1\right)}
\end{gathered}
$$

in which, $x$ denotes carbonation depth; $f_{1}(x)$ is the probability density of normal distribution of $x ; f_{2}(x)$ is the probability density of lognormal distribution of $x$.

In order to evaluate statistically the irregularity of the carbonation depth, the average probability density of carbonation depth measured from the experimental results shown in Figs. 6 (a), (b) and (c), respectively are compared with the probability density calculated from the analytical normal and the lognormal distribution functions defined in Eq. ((1) and Eq. ((2). Table 3 presents the parameters that are required to calculate the normal and the lognormal distribution probability densities of the tested carbonation depth by Eqs. ((1) and ((2) and were evaluated from the test results.

\begin{tabular}{|c|c|c|c|c|}
\hline \multirow{2}{*}{$\begin{array}{l}\text { Carbonation time, } \\
T \text { (h) }\end{array}$} & \multicolumn{2}{|l|}{ Normal distribution } & \multicolumn{2}{|l|}{ Lognormal distribution } \\
\hline & Average, $\mu_{l}(\mathrm{~mm})$ & $\begin{array}{l}\text { Standard deviation, } \sigma_{l} \\
(\mathrm{~mm})\end{array}$ & Log Average, $\mu_{2}(\mathrm{~mm})$ & $\begin{array}{l}\text { Log standard } \\
\text { deviation, } \sigma_{2}(\mathrm{~mm})\end{array}$ \\
\hline 4.5 & 7.8 & 3.5 & 2.0 & 0.4 \\
\hline 5.7 & 10.0 & 4.0 & 2.2 & 0.4 \\
\hline 7.5 & 11.6 & 4.5 & 2.4 & 0.4 \\
\hline
\end{tabular}

\section{Table 3}

Parameters for the normal and lognormal distributions probability density of the experimental carbonation depth.

The comparisons between the test results and the distributions calculated from Eq. ((1) and Eq. ((2) are shown in Fig. $\underset{\mathbf{8}}{\mathbf{8}}$. It can be seen that the probability density functions of carbonation depth of the three groups, i.e., for the blocks carbonated for $4.5 \mathrm{~h}, 5.7 \mathrm{~h}$ and $7.5 \mathrm{~h}$, can all be represented reasonably well by both the normal and the lognormal distribution functions, while the lognormal one shows better approximation. This is judged by comparing both the overall shape of the curves and also the carbonation depth at which the maximum probability density occurs. Obviously, the carbonation depth at which the probability density reaches maximum 
shows good agreement between the test results and the lognormal distribution function.

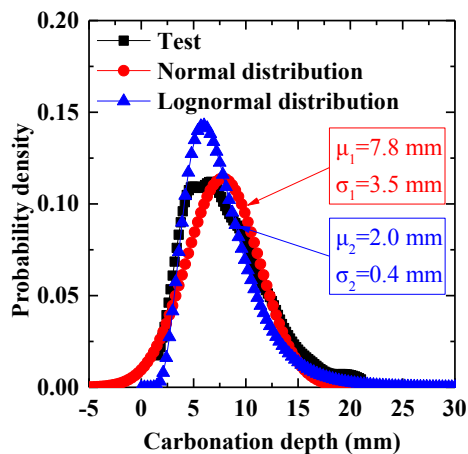

a) 4.5 hours for cement mortar

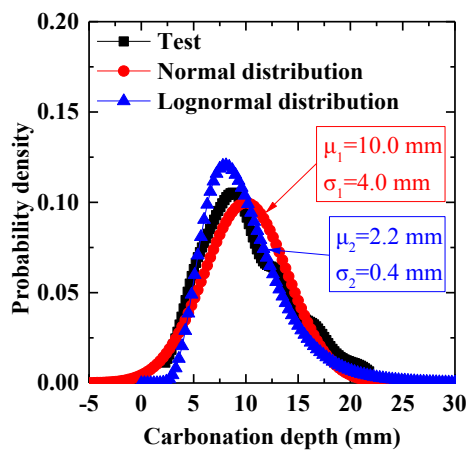

b) 5.7 hours for cement mortar

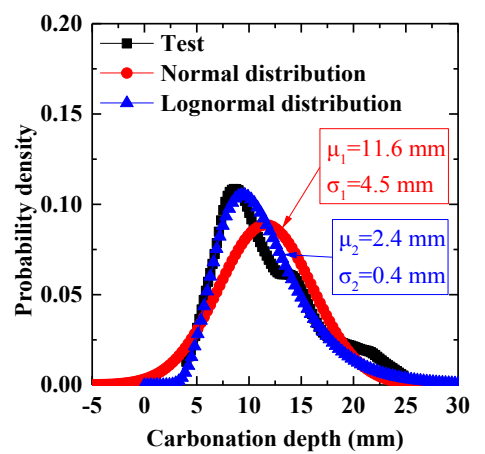

c) 7.5 hours for cement mortar

Fig. 8. Probability density function of test carbonation depth

\subsection{Power spectral density of the irregular experimental carbonation depth}

To quantitatively describe the random nature of the experimental carbonation depths, the PSD of them are studied in this Section. Before the PSD of the experimental carbonation depths is calculated, the raw data measured from the image process were pre-processed using a five-point running mean ${ }^{[41,42]}$ approach to remove some very high frequency elements, which can be potentially noises of the spectrum. The spectrum was also shifted downward by nullifying the carbonation depth represented by the trend line, which can eliminate the distortion of waveform caused by the deviation of the base line ${ }^{[43]}$. Fig. $\mathbf{9}$ shows how the date of sample-1 were processed from the non-zero baseline to the zero baseline distributions and that the processed curves become smoother after removing some of the high frequency.

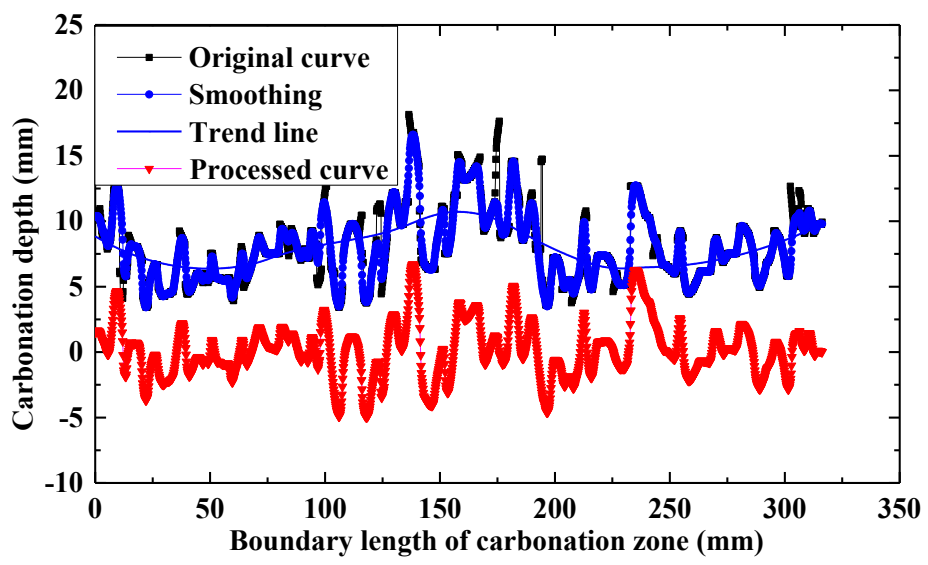

Fig. 9. Processing of experimental carbonation depth (sample-1)

To find the underlying rule of the randomly distributed carbonation depth of cement mortar, the PSD of carbonation depth is calculated below. Mathematically, PSD is calculated from the autocorrelation function as [44].

$$
P_{X X}(\omega)=\frac{2}{\pi} \int_{0}^{\infty} R_{X X}(\tau) \cos \omega \tau d \tau
$$

where $P_{X X}(\omega)$ is PSD; $\omega$ is frequency; $R_{X X}(\tau)$ is the autocorrelation function of $x(t) ; x(t)$ is the carbonation depth as a function of location along the boundary; $t$ and $\tau$ are the location co-ordinates along the boundary of the carbonation zone; $R_{X X}(\tau)$ can be expressed as ${ }^{[44]}$ : 


$$
R_{X X}(\tau)=\lim _{t_{\text {total }} \rightarrow \infty} \frac{1}{t_{\text {total }}} \int_{0}^{T} x(t) x(t+\tau) d t
$$

where $t_{\text {total }}$ is the total length of the boundary of carbonation zone. The PSD of the carbonation depth calculated from Eqs. ((5) and ((6) for the six samples of each of the three groups are, respectively, shown in Figs. 10 (a), (b) and (c). Fig. 10(d) presents the average PSD of each group. From observation, it was found that the distributions of the PSD for all the cases were close to a probability function of lognormal distribution. Therefore, curve fitting is used to present their respective average PSD explicitly in the form of probability function of lognormal distribution, as follows.

$$
P_{X X}(\omega)=\frac{1}{\sqrt{2 \pi} \sigma \omega} e^{-\frac{(\ln \omega-\mu)^{2}}{2 \sigma^{2}}}
$$

where $\mu$ and $\sigma$ are the parameters that are determined in the fitting process. As shown in Fig. 10(d), the fitted probability density function of lognormal distributions (solid lines) agree with their respective original data well. Thus, Eq. ((7) can be used with reasonable accuracy to represent the PSD of carbonation depth. In this paper, the frequency is defined as cycles completed within a unit length. It can be seen that carbonation time has little effect on the distribution of experimental carbonation depth in the frequency domain. For all the three cases, the power spectral density peaks approximate at a frequency of $0.015 \mathrm{~mm}^{-1}$ or $66.7 \mathrm{~mm}$ in wavelength.



a) 4.5 hours carbonation

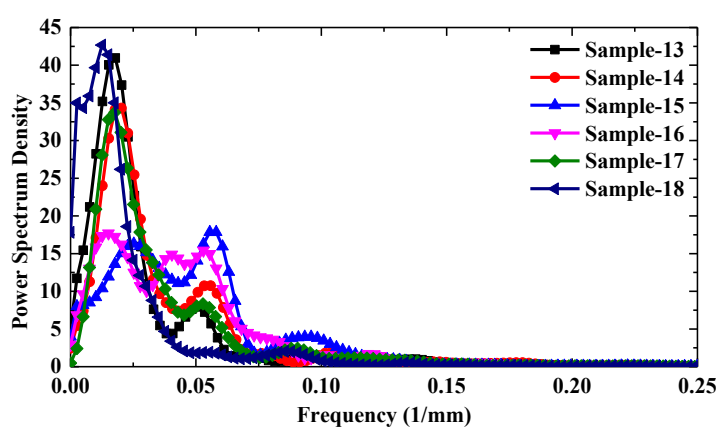

c) 7.5 hours carbonation



b) 5.7 hours carbonation

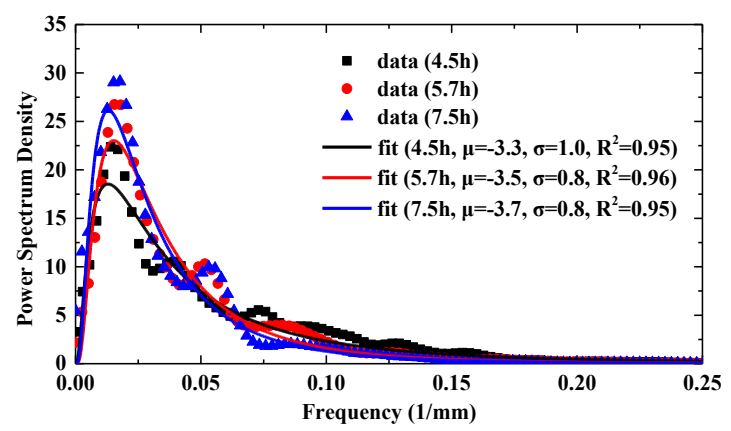

d) Average values of the 6 samples

Fig. 10. Power spectral density of carbonation depth

\section{Numerical investigation on the irregularity of carbonation depth}

In this section, the simulation results of the test cases are summarized and compared with the experimental results presented in Section 2. The effects of different carbonation time, coefficient of variation of porosity and 
the autocorrelation lengths on the average and variance of carbonation depth, probability density of irregular carbonation depth and the PSD of supercritical carbonation depth are discussed.

\subsection{Numerical simulation method of irregularity of carbonation depth}

\subsubsection{Introduction to the numerical model of carbonation depth}

In this section, the test results presented in Section 3 are used to validate the probability density and the PSD of the carbonation depth predicted by the 2-D Multiphysics supercritical carbonation model developed previously by the authors ${ }^{[24]}$, where a random field of porosity of cement-based on the method of the modified ellipsoidal autocorrelation function was used to simulate the random voids distribution. The developed random field model of porosity offered a porosity distribution ranged from 0 to 1 and considered the following spatial correlation by selecting the values of $a$ and $b^{[24]}$.

$$
\phi(x, y)=\exp \left[-\left(\frac{x^{2}}{a^{2}}+\frac{y^{2}}{b^{2}}\right)^{\frac{1}{1+r}}\right]
$$

where $\phi$ is an ellipsoidal autocorrelation function; $a$ and $b$ are the autocorrelation lengths in the $x$ and y directions, respectively; $r$ is the roughness factor (when $r=0$, it is the Gaussian autocorrelation function). In the previous work, it was assumed that the autocorrelation lengths, $a$ and $b$, in equation $(8)$ were both $0.005 \mathrm{~m}^{[24]}$. It was observed that the introduction of spatial correlation resulted in more realistic results than those from other random models without considering it. The random porosity model of cement mortar blocks, considering the spatial correlation, can satisfactorily capture the irregular boundaries of the non-carbonated zones. Therefore, it is clear that the autocorrelation lengths, $a$ and $b$, and coefficient of variation of porosity, $C V_{p}$, have played important roles in defining the topography of the carbonation front.

To simulate the random nature of the carbonation front, there are three main parameters that have to be considered, including the average porosity, the autocorrelation lengths and the coefficient of variation of porosity. The average porosity, 0.12 in this case, were obtained by mercury intrusion porosimetry. However, the autocorrelation lengths and the coefficient of variation of porosity cannot be directly measured easily. Therefore, numerical simulations, supported by experimental tests, can be used to evaluate the effect of autocorrelation lengths and coefficient of variation of porosity on the irregularity of carbonation depth, such that these parameters can be effectively validated.

\subsubsection{Test verification and analysis of numerical model}

In order to study the effects of the above two factors on the topography of carbonation depth, random porosity with autocorrelation lengths and coefficient of variation of porosity are studied. The average initial porosity is 0.12 from the mercury intrusion porosimetry test in Section 2.1. Other parameters used in the supercritical carbonation model are listed in Table 4 ,

Table 4

Parameters of supercritical carbonation model.

\begin{tabular}{ccc}
\hline Items & Value & References \\
\hline Intrinsic permeability, $k_{0}$ & $1.5 \times 10^{-20} \mathrm{~m}^{2}$ & {$[45]$} \\
Initial porosity, $n_{0}$ & 0.12 & From MIP \\
\hline
\end{tabular}




\begin{tabular}{ccc}
\hline Capillary pressure curve coefficient, $\alpha$ & $4 \times 10^{-8} \mathrm{~Pa}^{-1}$ & {$[45]$} \\
Relative permeability coefficient, $m$ & 0.49 & {$[45]$} \\
Relative humidity, $h_{0}$ & 0.82 & Measured \\
\hline
\end{tabular}

The random porosity field with different autocorrelation lengths and coefficients of variation of porosity are shown in Fig. 11, Figs. $\underline{11}(a),(b)$ and $(c)$ show the porosity distribution of a cement mortar that has a fixed coefficient of variation of porosity $C V_{p}=0.3$ and varying autocorrelation lengths, i.e., $a=b=0.005 \mathrm{~m}, 0.008 \mathrm{~m}$, $0.01 \mathrm{~m}$. Their respective carbonation profiles are shown in Figs. $\underline{\mathbf{1 1}}(d),(e)$ and $(f)$, where the effect of spatial correlation on carbonation depth is evident. Figs. $11(g),(h)$ and $(i)$ are the porosity distribution of the cement mortar with varying coefficient of variation of porosity $C V_{p}=0.1,0.2$ and 0.3 , while the autocorrelation length is fixed to $a=b=0.01 \mathrm{~m}$. The respective carbonation results are shown in Figs. 11 $(j),(k)$ and $(l)$.

Delet

Delet

Delet

Delet

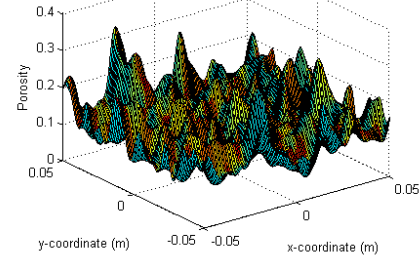

a) $a=b=0.005 \mathrm{~m}$

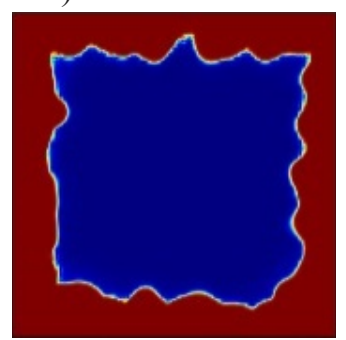

d) Carbonation of model (a)

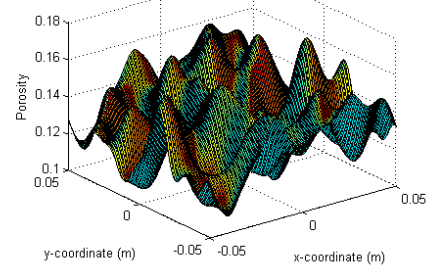

g) $C V_{p}=0.1$

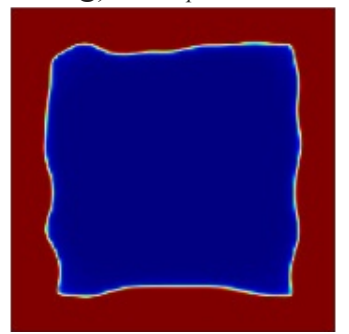

j) Carbonation of model (g)

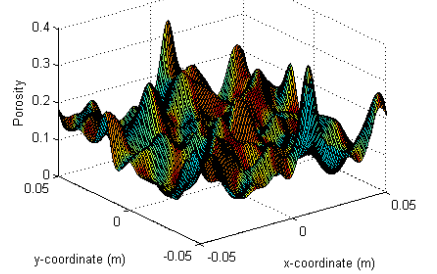

b) $a=b=0.008 \mathrm{~m}$

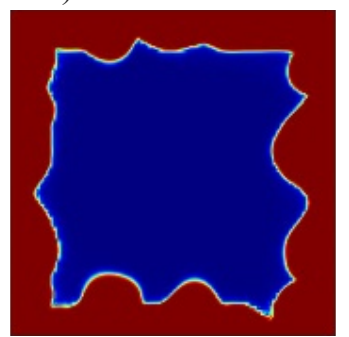

e) Carbonation of model (b)

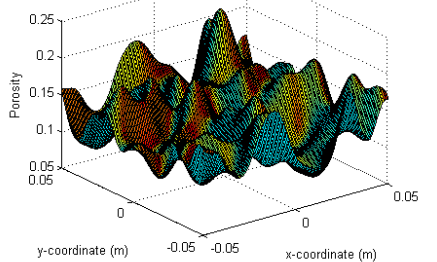

h) $C V_{p}=0.2$

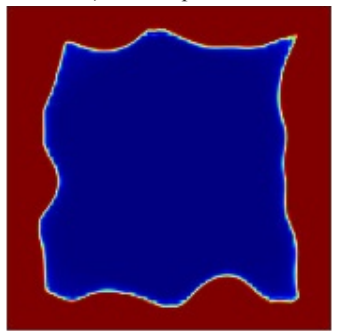

k) Carbonation of model (h)

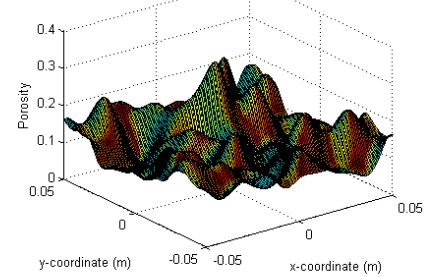

c) $a=b=0.01 \mathrm{~m}$

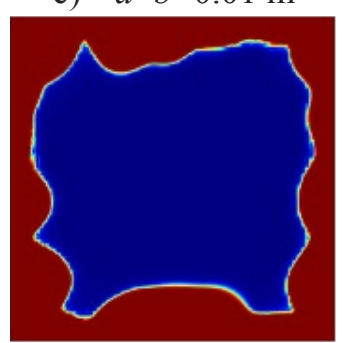

f) Carbonation of model (c)

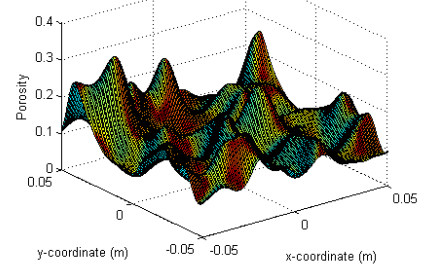

i) $C V_{p}=0.3$

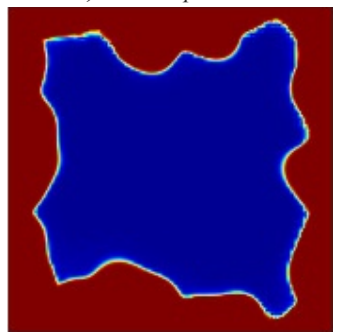

1) Carbonation of model (i)

Fig. 11. Random distribution of porosity and the corresponding carbonation results

All the cement mortar blocks tested in Section 2 were simulated in the supercritical condition using the numerical model presented in ${ }^{[3]}$ with a total carbonation time of 4.5, 5.7, 7.5 hours, respectively. For a given carbonation time, 6 samples with the same coefficient of variation and autocorrelation length were studied. For given values of $a, b$ and $C V_{p}, 18$ samples with varying properties were simulated. Therefore, a total of 162 cases 
were studied.

From the simulation results, the average carbonation depths and their average values of variance of each of the groups are calculated and listed in Table 5 , As expected, the average carbonation depth from the calculation increases with the increase of carbonation time. It is noted that the variance of the depth is also increasing with time. The effect of the autocorrelation lengths on the average carbonation depth are not significant. The variance of carbonation depth increases with an increase of the autocorrelation lengths, which explains well why use of the modified ellipsoidal autocorrelation function can pick up the random nature of carbonation depth caused by random porosity. The variance of carbonation depth increases also with an increase of the coefficient of variation of porosity. The effect of the coefficient of variation of porosity on the average carbonation depth are not significant.

\section{Table 5}

Average values of average carbonation depth and variance.

\begin{tabular}{|c|c|c|c|c|}
\hline \multirow[b]{2}{*}{$\begin{array}{c}\text { Carbonation time, } T \\
\text { (h) }\end{array}$} & \multirow[b]{2}{*}{$\begin{array}{c}\text { Autocorrelation length, } \\
a=b(\mathrm{~m})\end{array}$} & \multirow[b]{2}{*}{$\begin{array}{c}\text { Coefficient of variation of } \\
\text { porosity, } C V_{p}\end{array}$} & \multicolumn{2}{|c|}{ Average value } \\
\hline & & & $\begin{array}{c}\text { Carbonation depth, } \mu_{1} \\
(\mathrm{~mm})\end{array}$ & $\begin{array}{l}\text { Variance, } v_{l} \\
\quad\left(\mathrm{~mm}^{2}\right)\end{array}$ \\
\hline 4.5 & 0.01 & 0.3 & 9.3 & 10.8 \\
\hline 5.7 & 0.01 & 0.3 & 10.5 & 13.1 \\
\hline 7.5 & 0.01 & 0.3 & 12.2 & 16.0 \\
\hline 7.5 & 0.005 & 0.3 & 12.6 & 6.1 \\
\hline 7.5 & 0.008 & 0.3 & 13.2 & 7.4 \\
\hline 7.5 & 0.01 & 0.3 & 12.2 & 16.0 \\
\hline 7.5 & 0.01 & 0.1 & 12.4 & 1.5 \\
\hline 7.5 & 0.01 & 0.2 & 12.3 & 5.8 \\
\hline 7.5 & 0.01 & 0.3 & 12.2 & 16.0 \\
\hline
\end{tabular}

The comparisons shown in Figs. $\underline{12}$ (a) and (b) are, respectively, for the average carbonation depths obtained by using the three different autocorrelation lengths and coefficient of variation of porosity for a fixed carbonation time of $7.5 \mathrm{~h}$. Fig. $\underline{\mathbf{1 2}}$ (c) shows the comparisons of the test and simulation results when the autocorrelation lengths are fixed at $a=b=0.01 \mathrm{~m}$. In Fig. $\underline{\mathbf{1 2}}$, the colored bars represent the average carbonation depth and the error bars provide the maximum and minimum depths of each cases. In general, the model has predicted the average depth well and agreed satisfactorily with the test results, though the model slightly overestimates the average values and underestimates the scatters when a small value of $C V_{p}$ is used.

It is worth noting that the discrepancies between the test and simulation results can be attributed to other factors, such as the size and distribution of fine aggregates, the size of individual pores and micro cracks, etc. It is not possible, to take full consideration of all these in a macro scale model. Thus, the use of coefficients of variant and, especially, the introduction of the autocorrelation function in this paper aimed at offsetting the errors, which appeared to be reasonably effective. 


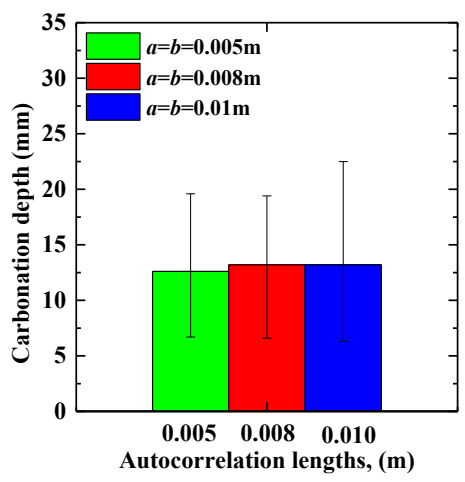

a) $C V_{p}=0.3$

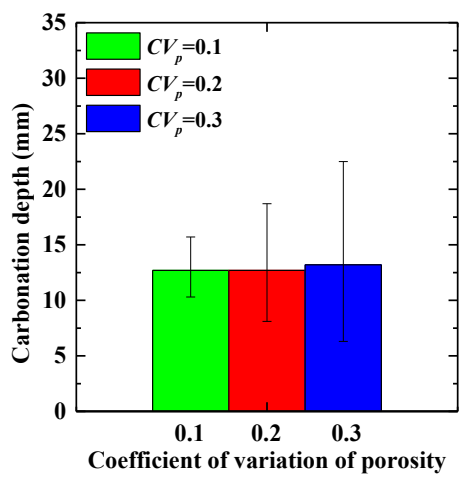

b) $a=b=0.010 \mathrm{~m}$

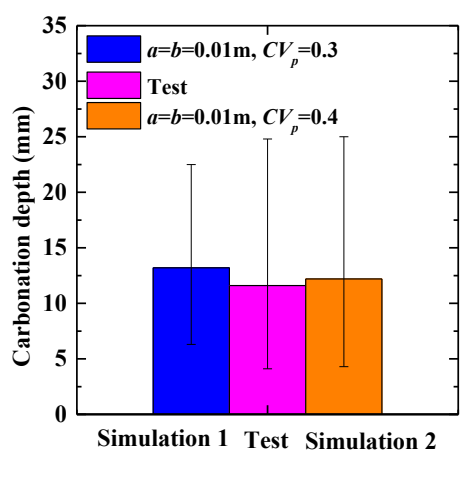

c) Comparison of test and simulated carbonation depth

Fig.

12. Test and simulated carbonation depth $(T=7.5 \mathrm{~h})$

\subsection{Effects of carbonation time on the irregularity of carbonation depth}

\subsubsection{Effects on the probability density of irregular carbonation depth}

In order to statistically describe the randomness of carbonation depth, the average probability density of carbonation depth of 6 cement mortar cubes were calculated from the simulations and compared with those calculated from the normal and the lognormal distribution equations ((1) and ((2). Without loss of generality, only one set of the results, which are for $a=b=0.01 \mathrm{~m}, C V_{p}=0.3$, are presented here. The parameters for calculating the normal distribution and the lognormal distribution probability densities from Eqs. ((1) and ((2) are taken from Fig. $\underline{13}$.

The comparisons are shown in Fig. $\underline{\mathbf{1 3}}$, It is observed that the probability density functions of carbonation depth for $4.5 \mathrm{~h}, 5.7 \mathrm{~h}$ and $7.5 \mathrm{~h}$ carbonation time all agree better with the lognormal than the normal distributions, judging again by both the overall shape of the curves and the horizontal position of the peak probability density.

Delet

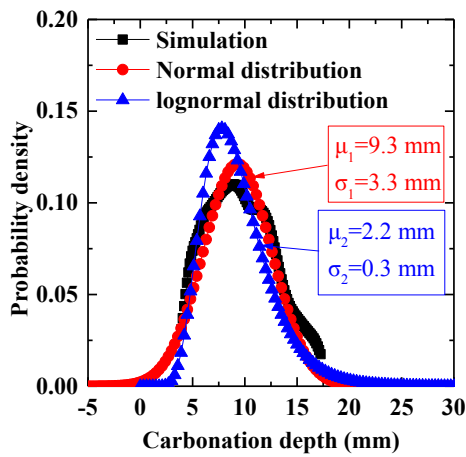

a) 4.5 hours carbonation

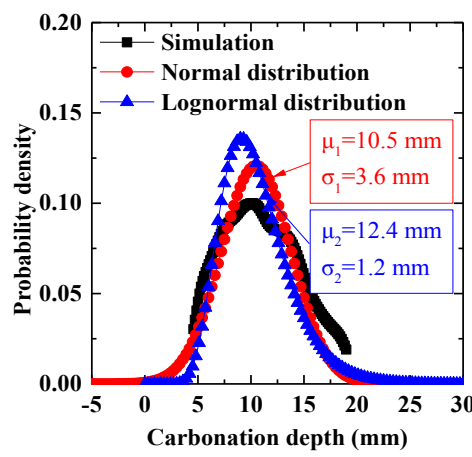

b) 5.7 hours carbonation

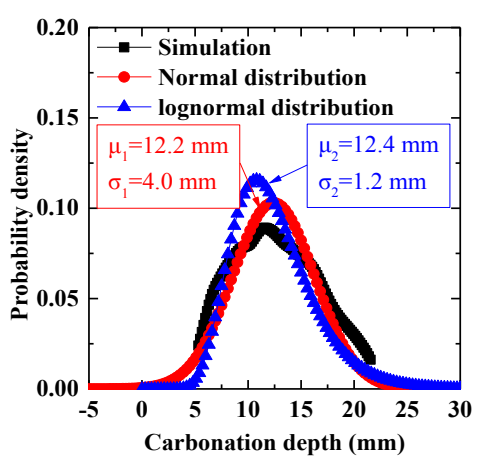

c) 7.5 hours carbonation

Fig. 13. Probability density function of the simulated carbonation depth ( $a=b=0.01 \mathrm{~m}, C V_{p}=0.3$ )

\subsubsection{Effects on the power spectral density of irregular carbonation depth}

In this Section, the simulated random carbonation depths are characterized by their PSD to quantitatively define the underlying rule of the irregularity of supercritical carbonation depth of cement mortar and the effects of carbonation time on the PSD. Without loss of generality, only the PSD of the carbonation depths shown in Table 5 are calculated and presented in Fig. 14(a), for a carbonation time of 4.5 hours. Fig. 14(b) shows the 
average PSD, where the PSD calculated from the respective test results are also presented for comparisons. From the comparisons, it can be observed that the carbonation time has little effect on the PSD distribution in the frequency domain and the frequency of maximum PSD.

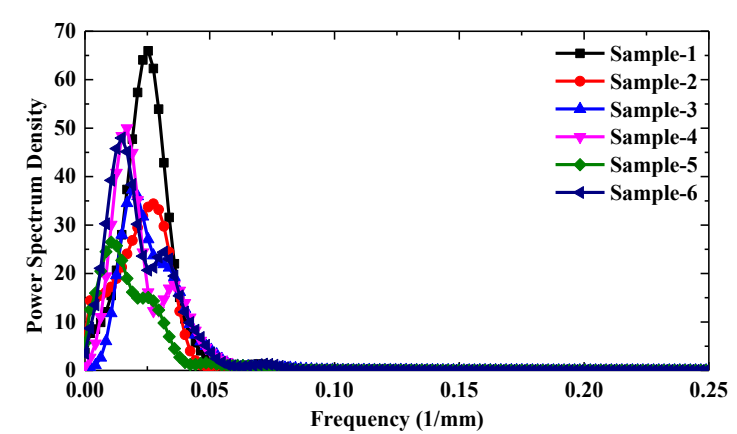

a) 4.5 hours carbonation

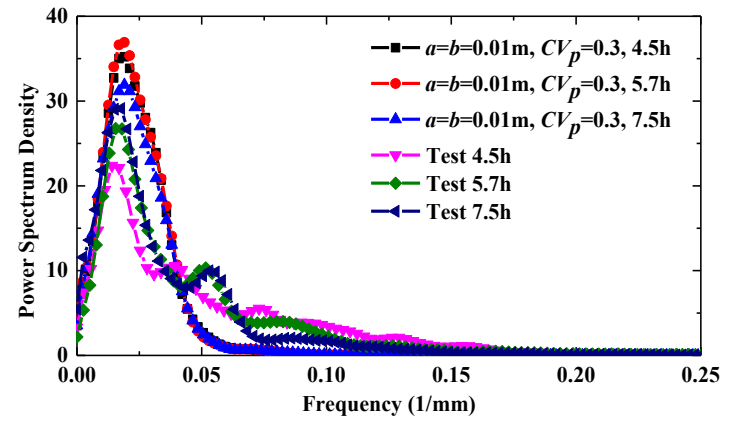

b) Average values of the 6 samples

Fig. 14. Power spectral density of numerical carbonation depth ( $a=b=0.01 \mathrm{~m}, C V_{p}=0.3$ )

\subsection{Effects of coefficient of variation and autocorrelation length of porosity on the irregularity of carbonation depth}

\subsubsection{Effects on the probability density of irregular carbonation depth}

In order to statistically describe the irregularity of carbonation depth, the average probability density of the carbonation depth of the 6 cement mortar cubes were calculated and compared with the normal and the lognormal distribution according to Eq. ((1) and Eq. ((2). Also without loss of generality, only selected sets of the results are presented here. Figs. 15 (a), (b) and (c) are the probability density for $a=b=0.01 \mathrm{~m}, C V_{p}=0.1,0.2,0.3$, and $T=7.5$ h. Figs. 15 (f), (g) and (h) are for $a=b=0.005 \mathrm{~m}, 0.008 \mathrm{~m}, 0.010 \mathrm{~m}, C V_{p}=0.3$, and $T=7.5 \mathrm{~h}$. The statistical distribution parameters are also shown in Fig. $\underline{\mathbf{1 5}}$

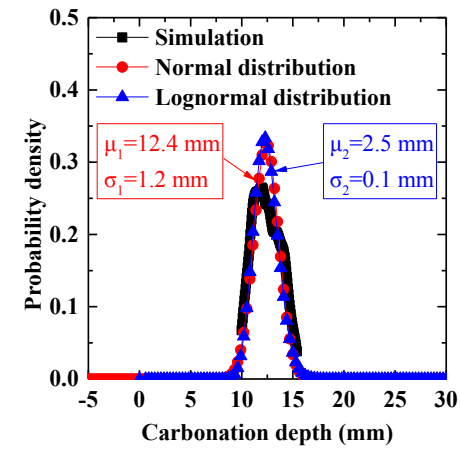

a) $C V_{p}=0.1, a=b=0.01 \mathrm{~m}$

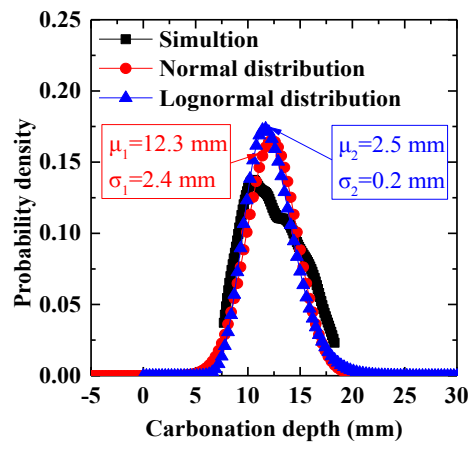

b) $C V_{p}=0.2, a=b=0.01 \mathrm{~m}$

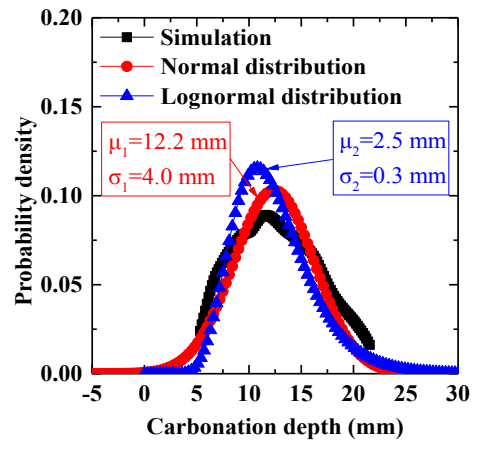

c) $C V_{p}=0.3, a=b=0.01 \mathrm{~m}$ 


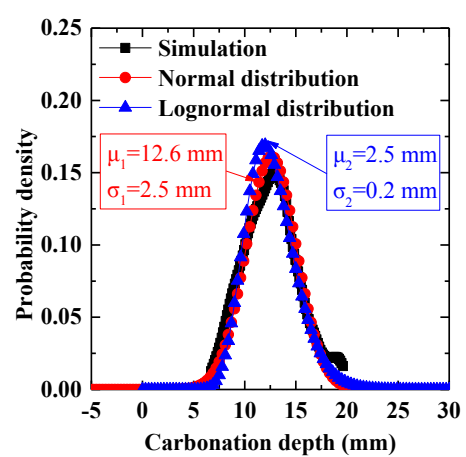

d) $a=b=0.005 \mathrm{~m}, C V_{p}=0.3$

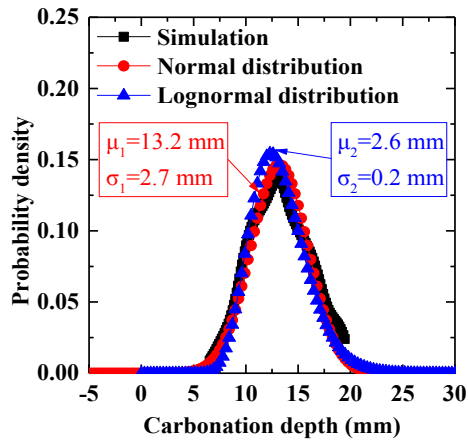

e) $a=b=0.008 \mathrm{~m}, C V_{p}=0.3$

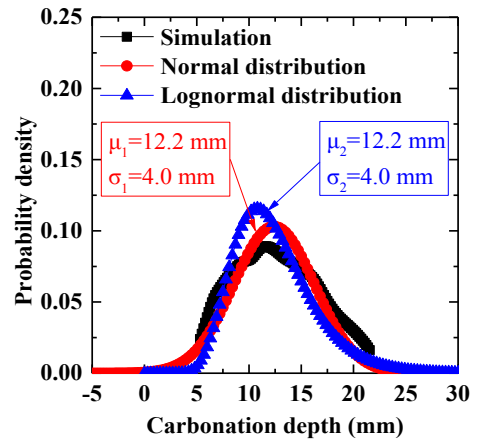

f) $a=b=0.01 \mathrm{~m}, C V_{p}=0.3$

Fig. 15. Probability density function of simulated carbonation depth $(T=7.5 \mathrm{~h})$

The comparisons from Fig. $\underline{\mathbf{1 5}}$ clearly show that the distributions from the simulations are closer to the lognormal distributions for all the cases, which confirmed the observation from Fig. $\underline{\mathbf{1 3}}$.

\subsubsection{Effects on the power spectral density of irregular carbonation depth}

The effects of coefficient of variation of porosity and the autocorrelation length on the PSD of carbonation depth are discussed below. Fig. 16. (a) is the average PSD of the carbonation depth of 6 cement mortar cubes for combinations of $a=b=0.005 \mathrm{~m}, C V_{p}=0.1,0.2,0.3$ at $T=7.5 \mathrm{~h}$. The frequency of maximum PSD at different autocorrelation lengths and with varying $C V_{p}$ are shown in Fig. 16(b). It can be seen that for the cement blocks the simulated frequencies of maximum PSDs are clearly affected by the chosen values of $a$ and $b$, and, in this case, have better agreement with the test results when $a=b=0.005 \mathrm{~m}$. For all the cases the PSD are not significantly affected by the varying $C V_{p}$.

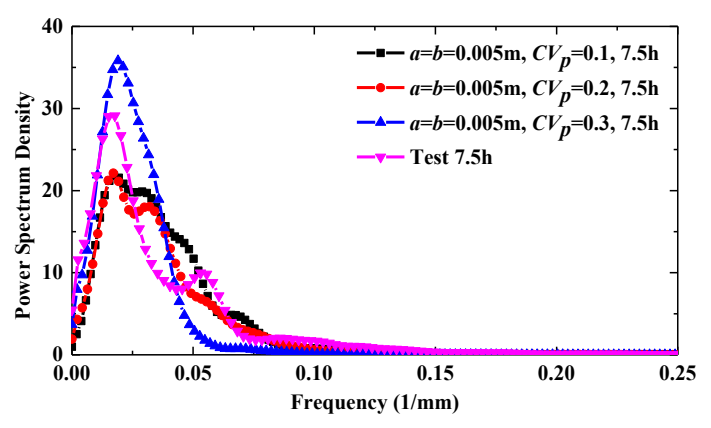

a) $a=b=0.005 \mathrm{~m}$

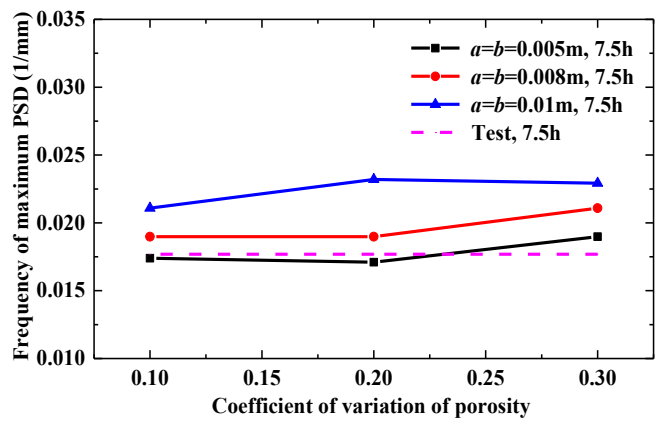

b) Frequencies of maximum PSD

Fig. 16. Effects of coefficient of variation of porosity on the power spectral density of carbonation depth $(T=7.5 \mathrm{~h})$

\section{Conclusions and outlook}

Experimental and numerical investigations on the irregularity of supercritical carbonation depth of cement mortar have been presented in this paper. The irregularity of supercritical carbonation depth of cement mortar was modelled by introducing random field of porosity to simulate the heterogeneous geometry of the carbonation profile. An image processing technique was proposed to effectively capture the distributions of carbonation depth from both the experiments and simulations. The random nature of the carbonation depths was then studied 
statistically by calculating the relevant average, variance, probability density and power spectrum density. Parametric studies were carried out to assess the effect of carbonation time, coefficient of variation of porosity and autocorrelation lengths of the random porosity field on the power spectral density of carbonation depth. From the present study, the following conclusions can be drawn:

1) The proposed image processing technique can be used satisfactorily to capture the random distribution of carbonation depth of cement mortar.

2) The average and variance of the irregular carbonation depth increase with the increase of carbonation time, autocorrelation length and coefficient of variation of porosity.

3) Both the experimental and the numerical results indicate that the probability density function of carbonation depth is better represented by the lognormal than the normal distributions.

4) The carbonation time and the coefficient of variation of porosity have little effect on the frequency of maximum PSD of carbonation depth that, however, increases as the autocorrelation depth increases. This unique feature can be used to calibrate the values of autocorrelation length, which are critically important in the numerical carbonation model.

5) To have better and more realistic understanding of carbonation depth formation, further studies are required to include random distribution of aggregates, micro cracks and varying composition in the statistical model. To this end, further experiments will be carried out and new algorithms for generating random aggregates and micro cracks are to be developed.

\section{Acknowledgement}

The authors are grateful for the financial support from the National Key Research and Development Program of China (2016YFC0701400).

\section{References}

[1] Shen J, Dangla P, Thiery M. Reactive Transport Modeling of $\mathrm{CO}_{2}$ through Cementitious Materials under $\mathrm{CO}_{2}$ Geological Storage Conditions. International Journal of Greenhouse Gas Control, 2013, 18: 75-87.

[2] Maekawa K, T I, T K. Multi-Scale Modeling of Structural Concrete. Taylor\&Francis, 2009.

[3] Zha X, Yu M, Ye J, et al. Numerical Modeling of Supercritical Carbonation Process in Cement-Based Materials. Cement and Concrete Research, 2015, 72: 10-20.

[4] Phung Q T, Maes N, Jacques D, et al. Modelling the Carbonation of Cement Pastes Under a $\mathrm{CO}_{2}$ Pressure Gradient Considering Both Diffusive and Convective Transport. Construction and Building Materials, 2016, 114: 333-351.

[5] Saetta A V, Schrefler B A, Vitaliani R V. The Carbonation of Concrete and the Mechanism of Moisture, Heat and Carbon-Dioxide Flow-through Porous Materials. Cement and Concrete Research, 1993, 23(4): 761-772.

[6] Aavija B, Luković M. Carbonation of Cement Paste: Understanding, Challenges, and Opportunities. Construction and Building Materials, 2016, 117: 285-301.

[7] Ashraf W. Carbonation of Cement-Based Materials: Challenges and Opportunities. Construction and Building Materials, 2016, 120: 558-570.

[8] Ann K Y, Pack S W, Hwang J P, et al. Service Life Prediction of a Concrete Bridge Structure Subjected to Carbonation. Construction and Building Materials, 2010, 24(8): 1494-1501.

[9] Enright M P, Frangopol D M. Service-Life Prediction of Deteriorating Concrete Bridges. 1998, 124(3): 
309-317.

[10] Rubin J B, Carey J W, Taylor C. Enhancement of Cemented Waste Forms by Supercritical $\mathrm{CO}_{2}$ Carbonation of Standard Portland Cements[M]//1997: 473-478.

[11] García-González C A, Hidalgo A, Andrade C, et al. Modification of Composition and Microstructure of Portland Cement Pastes as a Result of Natural and Supercritical Carbonation Procedures. Industrial \& Engineering Chemistry Research, 2006, 45(14): 4985-4992.

[12] Purnell P, Seneviratne A M G, Short N R, et al. Super-Critical Carbonation of Glass-Fibre Reinforced Cement. Part 2: Microstructural Observations. Composites Part a: Applied Science and Manufacturing, 2003, 34(11): 1105-1112.

[13] G Feng. Experimental and Numerical Study of Accelerated Carbonation in Cement Brick and Tile. Harbin Institute of Technology, Master Degree in Engineering, 2013. (in Chinese)

[14] Zhan B, Poon C, Shi C. $\mathrm{CO}_{2}$ Curing for Improving the Properties of Concrete Blocks Containing Recycled Aggregates. Cement and Concrete Composites, 2013, 42: 1-8.

[15] Kou S, Zhan B, Poon C. Use of a $\mathrm{CO}_{2}$ Curing Step to Improve the Properties of Concrete Prepared with Recycled Aggregates. Cement and Concrete Composites, 2014, 45: 22-28.

[16] Hainer S, Proske T, Graubner C. Einfluss Der Nachbehandlung Auf Das Karbonatisierungsverhalten Von Beton Aus Klinkerarmen Zementen. Beton- Und Stahlbetonbau, 2015, 110(1): 41-49.

[17] Zha X, Wang H, Xie P, et al. Leaching Resistance of Hazardous Waste Cement Solidification After Accelerated Carbonation. Cement and Concrete Composites, 2016, 72: 125-132.

[18] Fernandezbertos M, Simons S, Hills C, et al. A Review of Accelerated Carbonation Technology in the Treatment of Cement-Based Materials and Sequestration of $\mathrm{CO}_{2}$. Journal of Hazardous Materials, 2004, 112(3): 193-205.

[19] Venhuis M A, Reardon E J. Vacuum Method for Carbonation of Cementitious Wasteforms. Environmental Science \& Technology, 2001, 35(20): 4120-4125.

[20] Zhang J, Shi C, Li Y, et al. Influence of Carbonated Recycled Concrete Aggregate on Properties of Cement Mortar. Construction and Building Materials, 2015, 98: 1-7.

[21] Xuan D, Zhan B, Poon C S. Assessment of Mechanical Properties of Concrete Incorporating Carbonated Recycled Concrete Aggregates. Cement and Concrete Composites, 2016, 65: 67-74.

[22] Thiery M, Dangla P, Belin P, et al. Carbonation Kinetics of a Bed of Recycled Concrete Aggregates: A Laboratory Study on Model Materials. Cement and Concrete Research, 2013, 46: 50-65.

[23] Beasley K J. Carbon Dating Concrete Cracks. Journal of Performance of Constructed Facilities, 2015, 29(025140021).

[24] Yu M, Bao H, Ye J, et al. The Effect of Random Porosity Field on Supercritical Carbonation of CementBased Materials. Construction and Building Materials, 2017, 146: 144-155.

[25] Samouh H, Soive A, Rozière E, et al. Experimental and Numerical Study of Size Effect on Long-Term Drying Behavior of Concrete: Influence of Drying Depth. Materials and Structures, 2016, 49(10): 40294048.

[26] Chang C, Chen J. The Experimental Investigation of Concrete Carbonation Depth. Cement and Concrete Research, 2006, 36(9): 1760-1767.

[27] Huang Q, Jiang Z, Zhang W, et al. Numerical Analysis of the Effect of Coarse Aggregate Distribution on Concrete Carbonation. Construction and Building Materials, 2012, 37: 27-35.

[28] Ruan X, Pan Z. Mesoscopic Simulation Method of Concrete Carbonation Process. Structure and Infrastructure Engineering, 2012, 8(2): 99-110.

[29] Ma R, Zhang J, Diao B. Research on the Carbonation Model of Stress Concrete Components [M]//CHING X, DVORIK V. Advances in Intelligent Systems Research. 2015:191-195.

[30] Yang C C, Cho S W. Influence of Aggregate Content on the Migration Coefficient of Concrete Materials 
Using Electrochemical Method. Materials Chemistry and Physics, 2003, 80(3): 752-757.

[31] Han J, Liu W, Wang S, et al. Effects of Crack and ITZ and Aggregate on Carbonation Penetration Based on 3D Micro X-Ray Ct Microstructure Evolution. Construction and Building Materials, 2016, 128: 256271.

[32] Han J, Liu W, Wang S, et al. Carbonation Reaction and Microstructural Changes of Metro-Tunnel Segment Concrete Coupled with Static and Fatigue Load. Journal of Materials in Civil Engineering, 2017, 29(040162162).

[33] Jiang C, Gu X, Zou W. An Experimental Study on Carbonation in the Tensile Zone of Fatigue-Damaged Plain Concrete Beams. Key Engineering Materials, 2016, 711: 751-758.

[34] Duparre A, Ferre-Borrull J, Gliech S, et al. Surface Characterization Techniques for Determining the RootMean-Square Roughness and Power Spectral Densities of Optical Components. Appl Opt, 2002, 41(1): 154-171.

[35] Leach R K. Chapter 1-Introduction to Metrology for Micro- and Nanotechnology [M]//Fundamental Principles of Engineering Nanometrology. Oxford: William Andrew Publishing, 2010: 1-4.

[36] Huang J, Peng Q, Hu X, et al. A Combined-Alpha-Shape-Implicit-Surface Approach to Generate 3D Random Concrete Mesostructures Via Digital Image Processing, Spectral Representation, and Point Cloud. Construction and Building Materials, 2017, 143: 330-365.

[37] Ferraioli M, Abruzzese D, Miccoli L, et al. Torsional Seismic Response of an Asymmetric- Plan Hospital Building: 14th Conference of seismic engineering ANIDIS, Bari, Italy, 2011 [C].

[38] Ervin B L, Kuchma D A, Bernhard J T, et al. Monitoring Corrosion of Rebar Embedded in Mortar Using High-Frequency Guided Ultrasonic Waves. 2009, 135(1): 9-19.

[39] Jacobs T, Junge T, Pastewka L. Quantitative Characterization of Surface Topography Using Spectral Analysis. 2016.

[40] Crowder M. A Statistical Approach to a Deterioration Process in Reinforced Concrete. Journal of the Royal Statistical Society, 1991, 40(1): 95-103.

[41] Windig W, Stephenson D A. Self-Modeling Mixture Analysis of Second-Derivative Near-Infrared Spectral Data Using the Simplisma Approach. 1992, 64(22): 2735-2742.

[42] Jaramillo C, Rueda M J, Mora G. Cenozoic Plant Diversity in the Neotropics. Science, 2006, 311(5769): 1893-1896.

[43] W Ji, H Xiao. The application of Matlab in processing of vibration signal. China Water \& Power Press, 2006. (in Chinese)

[44] Shou M C, Leu L P. Energy of Power Spectral Density Function and Wavelet Analysis of Absolute Pressure Fluctuation Measurements in Fluidized Beds. Chemical Engineering Research and Design, 2005, 83(5): 478-491.

[45] Baroghel-Bouny V, Thiéry M, Wang X. Modelling of Isothermal Coupled Moisture-Ion Transport in Cementitious Materials. Cement and Concrete Research, 2011, 41(8): 828-841. 